\title{
Pengaruh Pengungkapan Corporate Social Responsibility Terhadap Kinerja Keuangan Perbankan Indonesia (Studi Komparatif Perbankan BUMN dan Swasta)
}

\author{
Karina Odia Julialevi *1, Wita Ramadhanti \\ ${ }^{1,2}$ Program Studi Akuntansi, Fakultas Ekonomi dan Bisnis, Universitas Jenderal Soedirman, Indonesia \\ Email : ${ }^{1}$ karinaodiajulialevi@unsoed.ac.id
}

\begin{abstract}
Abstrak
Tujuan penelitian ini adalah untuk menguji pengaruh pengungkapan corporate social responsibility (CSR) terhadap kinerja keuangan perusahaan perbankan yang terdaftar di Bursa Efek Indonesia yang diproksikan oleh indikator keuangan berupa ROA, ROE, NIM dan CAR. Populasi dalam penelitian ini adalah seluruh perusahaan perbankan di Indonesia dari tahun 2012 sampai dengan 2014. Prosedur pemilihan sampel adalah purposive sampling sehingga diperoleh 20 perusahaan. Model penelitian yang digunakan sebagai alat uji adalah partial least square (PLS) dan Chow Test untuk melihat perbedaan pengaruhnya. Hasil penelitian menunjukkan bahwa pengungkapan corporate social responsibility berpengaruh secara positif terhadap kinerja keuangan perusahaan perbankan yang diproksikan oleh indikator ROA, ROE, dan CAR, baik perbankan berstatus BUMN maupun berstatus Swasta. Sementara untuk indikator NIM tidak berpengaruh secara positif oleh pengungkapan corporate social responsibility baik perbankan berstatus BUMN maupun Swasta. Untuk perbedaan pengaruh menggunakan Chow Test diketahui bahwa untuk indikator ROE terdapat perbedaan pengaruh pengungkapan corporate social responsibility antara perusahaan perbankan BUMN dan Swasta. Sementara untuk indikaor ROA, NIM dan CAR tidak terdapat perbedaan pengaruh.
\end{abstract}

Kata kunci: Capital Adequacy Ratio, Net Interest Margin, Corporate Social Responsibility, Return On Asset, Return On Equity.

\section{The Effect Of Corporate Social Responsibility Disclosure On Indonesian Banking Financial Performance (Comparative Study of BUMN and Private Banking)}

\begin{abstract}
The purpose of this study was to examine the effect of disclosure of corporate social responsibility (CSR) to the financial performance of banking companies listed in Indonesia Stock Exchange proxied by financial indicators such as ROA, ROE, NIM and CAR. The population in this study are all banking companies in Indonesia from 2012 to 2014. The sample selection procedure is purposive sampling so acquired 20 companies. The research model is used as a test tool is partial least square (PLS) and Chow Test.The results show that the disclosure of corporate social responsibility positively affect the company's financial performance indicators of banking proxied by the ROA, ROE, and CAR, both state-owned banks or private status. As for the NIM indicator is not affected positively by the disclosure of corporate social responsibility both state-owned and private banks. To difference of effect using Chow Test for the indicator ROE is known that there are differences in the effect of disclosure of corporate social responsibility between the state and private banking company. As for indicator ROA, NIM and CAR there is no difference effect.
\end{abstract}

Keywords: Capital Adequacy Ratio, Corporate Social Responsibility, Net Interest Margin, Return On Asset, Return On Equity.

\section{PENDAHULUAN}

Sustainable banking atau disebut juga dengan perbankan berkelanjutan merupakan keputusan bank untuk menyediakan produk dan jasa layanan perbankan dengan mempertimbangkan dampak terhadap lingkungan dan sosial[1]. Bisnis perbankan menjalankan aktivitas green banking dalam partisipasinya menuju pembangunan yang berkelanjutan. Awal mula perbankan menerapkan sustainability ketika Bank Indonesia meregulasi aturan melalui PBI No. 7/2/PBI/2005 yang menilai prospek usaha berdasarkan aspek lingkungan[2]. Pada bulan Desember tahun 2014 sesaat setelah OJK didirikan, maka dipublikasikan Roadmap Sustainable Finance yang mendukung perbankan dan lembaga jasa keuangan yang lainnya melakukan pembangunan berkelanjutan[1]. 
Salah satu bentuk kepedulian perbankan dalam berpartisipasi pada pembangunan berkelanjutan yaitu dengan mengadakan program CSR karena CSR sangat erat hubungannya dengan pembangunan berkelanjutan. Corporate Social Responsibility (CSR) merupakan bentuk tanggungjawab perusahaan kepada stakeholder serta shareholder dengan melakukan upaya untuk meminimalkan dampak negatif dari kegiatan usaha yang dilakukan juga memberikan manfaat di masa yang akan datang. Kegiatan CSR dalam bentuk community development, charity, maupun philanthropy yang saat ini berkembang di Indonesia masih berupa pengabdian kepada masyarakat atau lingkungan di sekitar berdirinya lokasi usaha padahal elemen CSR lebih luas berkaitan dengan aspek keuangan, soaial, serta lingkungan yang biasa disebut triple bottom line. Konsep ini perlu dikembangkan dan diperluas menjadi kegiatan CSR yang benar-benar sustainable.

Dengan melihat fungsi CSR maka semakin banyak perusahaan termasuk perusahaan perbankan yang menerapkan adanya CSR pada perusahaannya. CSR tidak hanya sebuah kesukarelaan, namun telah menjadi tuntutan agar perusahaan dapat bertahan dan berkembang. CSR yang dilakukan perbankan turut menentukan keberhasilan dalam jangka panjang sehingga akan meningkatkan nasabah yang juga akan meningkatkan pendapatan serta keuntungan bank. Hal ini akan berdampak baik pada kinerja perbankan.

Kinerja keuangan adalah aspek perusahaan yang dinilai oleh para investor yang mencerminkan kinerja perusahaan tersebut. Penjelasan yang berhubungan dengan kinerja keuangan dapat dilihat pada laporan keuangan perusahaan menggunakan rasio keuangannya. Informasi dari rasio keuangan ini digunakan untuk mendeteksi baik maupun tidaknya kinerja perusahaan. Rasio keuangan yang dapat mencerminkan kinerja keuangan yaitu dengan rasio profitabilitas yang diwakilkan dengan ROA, ROE, NIM dan CAR. Profitabilitas dan CSR saling terkait dalam mencerminkan padangan berdasarkan reaksi sosial di masyarakat[3].

Penelitian [4] menghasilkan CSR mempunyai pengaruh terhadap kinerja keuangan. Serupa dengan penelitian Susanto dan Tarigan[5]. Namun, bertolak belakang dengan [6]. Berdasarkan research gap dengan hasil penelitian yang berbeda dan temuan ketidakkonsistenan maka dilakukan analisis kembali mengenai CSR dan kinerja keuangan. Selain itu pentingnya perusahaan perbankan terhadap perekonomian di Indonesia membuat perusahaan perbankan menjadi penting untuk diteliti. Pada penelitian ini dilakukan komparasi pengungkapan CSR yang dilakukan oleh bank pemerintah dan bank swasta. Bank swasta lebih berekspektasi untuk mendapatkan keuntungan yang maksimal. Berbeda dengan bank pemerintah yang melaksanakan kinerja dengan standar undang-undang dan regulasi yang berlaku. Dalam pengambilan keputusan, bank pemerintah akan lebih memprioritaskan untuk menjaga stabilitas ekonomi Negara dibandingkan dengan untuk memaksimalkan keuntungan semata. Adanya perbedaan antara bank swasta dan pemerintah tersebut maka menyebabkan berbedaan tindakan yang dilakukan perusahaan, antara lain perbedaan dalam melaksanakan CSR.

Berdasarkan latar belakang yang telah dipaparkan menunjukkan bahwa terdapat perbedaan hasil pada penelitian terdahulu. Sehubungan dengan hal tersebut peneliti tertarik untuk kembali melakukan penelitian mengenai pengaruh pengungkapan Corporate Social Responsibility (CSR) terhadap kinerja keuangan perusahaan perbankan berstatus BUMN dan Swasta Nasional.

\section{METODE PENELITIAN}

Tabel 1. Definisi Operasional

\begin{tabular}{|c|c|c|c|}
\hline No. & Variabel & Definisi Operasional & Pengukuran \\
\hline 1. & $\begin{array}{l}\text { Corporate } \\
\text { Social } \\
\text { Responsibility } \\
\text { (CSR) }\end{array}$ & $\begin{array}{l}\text { Suatu bentuk kepedulian dari perusahaan } \\
\text { dengan indikator kepedulian lingkungan, } \\
\text { ketenagakerjaan, sosial HAM, kemasyarakatan, } \\
\text { dan tanggung jawab produk. }\end{array}$ & $\operatorname{CSRDI}_{J}=\frac{\sum X_{i j}}{N_{j}}$ \\
\hline 2. & $\begin{array}{l}\text { Return on } \\
\text { Assets (ROA) }\end{array}$ & 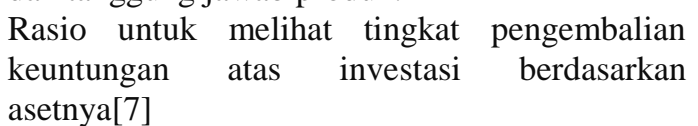 & $R O A=\frac{\text { Laba Bersih }}{\text { Total Aset }} \times 100 \%$ \\
\hline 3. & $\begin{array}{l}\text { Return on } \\
\text { Equity (ROE) }\end{array}$ & $\begin{array}{l}\text { Rasio pengembalian laba atas kemampuannya } \\
\text { menggunakan ekuitas yang dimiliki } \\
\text { perusahaan[7] }\end{array}$ & $R O E=\frac{\text { Laba Bersih }}{\text { Ekuitas }} \times 100 \%$ \\
\hline 4. & $\begin{array}{l}\text { Net Interest } \\
\text { Margin (NIM) }\end{array}$ & $\begin{array}{l}\text { Rasio untuk mengukur efisiensi perusahaan } \\
\text { berdasarkan pendapatan bunga bersih terhadap } \\
\text { rata-rata aset yang produktif[8] }\end{array}$ & $\begin{array}{l}\text { NIM } \\
=\frac{\text { Pendapatan Bunga Bersih }}{\text { Rata }- \text { rata Aset Produktif }}\end{array}$ \\
\hline 5. & $\begin{array}{l}\text { Capital } \\
\text { Adequacy } \\
\text { Ratio (CAR) }\end{array}$ & $\begin{array}{l}\text { Rasio yang digunakan bank untuk mengukur } \\
\text { kemampuan bank mencukupi modal yang } \\
\text { disebabkan penurunan aset agar terhindar dari } \\
\text { risiko[9] }\end{array}$ & $C A R=\frac{\text { Modal Bank }}{A T M R} \times 100 \%$ \\
\hline
\end{tabular}


Jenis penelitian ini termasuk pada tipe penelitian kuantitatif. Populasi yang diamati yakni perbankan konvensional yang berstatus BUMN dan Swasta Nasional yang terdaftar di BEI tahun 2012 - 2014 sebanyak 30 perusahaan. Data sampel yang diamati dipilih menggunakan teknik purposive sampling sebanyak 20 perusahaan. Pengumpulan data dilakukan dengan metode dokumentasi. Data diambil dari laporan keuangan perusahaan berupa data sekunder. Teknik analisis data dalam penelitian ini dilakukan PLS (Partial Least Square) versi Warp PLS .4.0. Berikut definisi operasional dari masing-masing variable dapat ditunjukkan oleh Tabel 1.

\section{HASIL DAN PEMBAHASAN}

\section{Pengujian Hipotesis}

Pengujian hipotesis dengan melihat nilai Path Coefficients dan p-values dan signifikansi pengaruh $\mathrm{X}$ terhadap Y yaitu CSR terhadap ROA, ROE, NIM dan CAR.

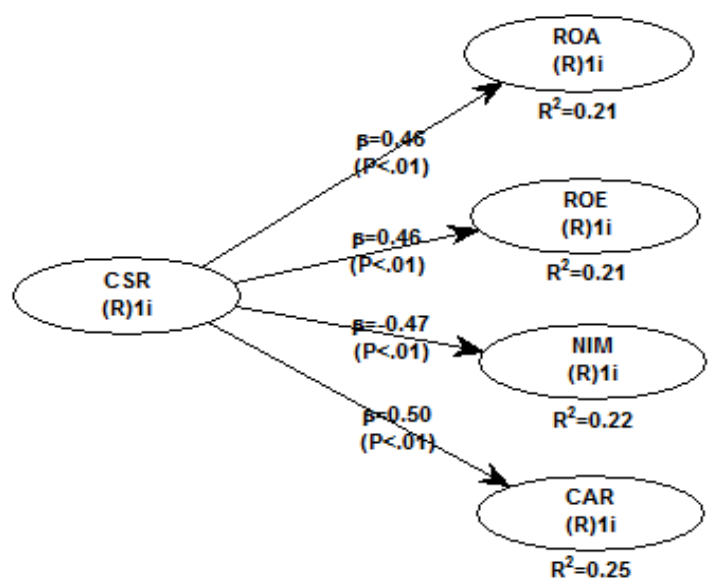

Gambar 1. Grafik output PLS kelompok Bank BUMN

Berdasarkan Gambar 1 menunjukkan bahwa nilai Path Coefficients dan p-values dari CSR ke ROA sebesar 0,46 dan 0,01 dan nilai $\mathrm{R}^{2}$ sebesar 0,21. Nilai Path Coefficients dan p-values dari CSR ke ROE sebesar 0,46 dan 0,01 dan nilai $\mathrm{R}^{2}$ sebesar 0,21. Nilai Path Coefficients dan p-values dari CSR ke NIM sebesar -0,47 dan 0,01 dan nilai $\mathrm{R}^{2}$ sebesar 0,22. Nilai Path Coefficients dan p-values dari CSR ke CAR sebesar 0,50 dan 0,01 dan nilai $\mathrm{R}^{2}$ sebesar 0,25 .

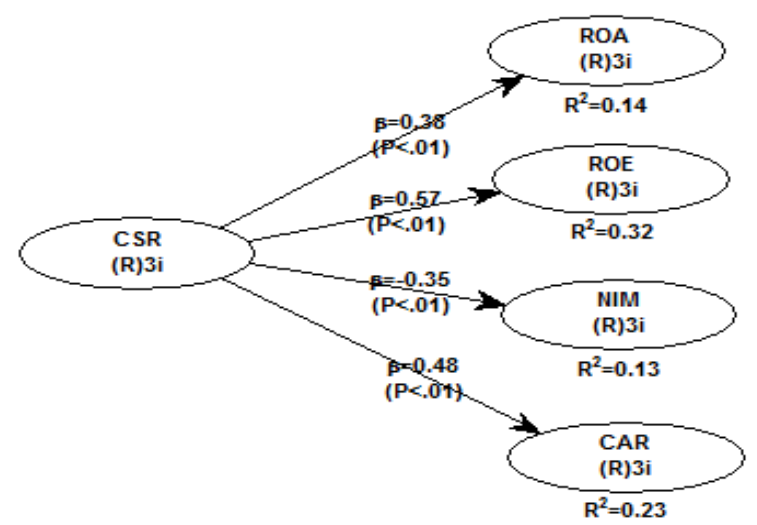

Gambar 2. Grafik output PLS kelompok Bank Swasta

Berdasarkan Gambar 2 menunjukkan bahwa nilai Path Coefficients dan p-values dari CSR ke ROA sebesar 0,38 dan 0,01 dan nilai $\mathrm{R}^{2}$ sebesar 0,14. Nilai Path Coefficients dan p-values dari CSR ke ROE sebesar 0,57 dan 0,01 dan nilai $\mathrm{R}^{2}$ sebesar 0,32. Nilai Path Coefficients dan p-values dari CSR ke NIM sebesar -0,35 dan 0,01 dan nilai $\mathrm{R}^{2}$ sebesar 0,13. Nilai Path Coefficients dan p-values dari CSR ke CAR sebesar 0,48 dan 0,01 dan nilai $\mathrm{R}^{2}$ sebesar 0,23 . 
Tabel 2. Ringkasan Penerimaan Hipotesis

\begin{tabular}{ccccc}
\hline Hipotesis & B & p value & Sig* & Keterangan \\
\hline CSR terhadap ROA BUMN (H1a) & 0,46 & 0,01 & 0,05 & Diterima \\
CSR terhadap ROE BUMN (H2a) & 0,46 & 0,01 & 0,05 & Diterima \\
CSR terhadap NIM BUMN (H3a) & $-0,47$ & 0,01 & 0,05 & Ditolak \\
CSR terhadap CAR BUMN (H4a) & 0,5 & 0,01 & 0,05 & Diterima \\
CSR terhadap ROA Swasta (H1b) & 0,38 & 0,01 & 0,05 & Diterima \\
CSR terhadap ROE Swasta (H2b) & 0,57 & 0,01 & 0,05 & Diterima \\
CSR terhadap NIM Swasta (H3b) & $-0,35$ & 0,01 & 0,05 & Ditolak \\
CSR terhadap CAR Swasta (H4b) & 0,48 & 0,01 & 0,05 & Diterima \\
\hline
\end{tabular}

Sumber : data diolah

\section{Pengujian Chow Test}

Model regresi Chow Test digunakan pada hipotesis 5 untuk membedakan hasil regresi pada bank berstatus BUMN dan bank berstatus swasta nasional digunakan.

Tabel 3. Penerimaan model regresi Chow Test

\begin{tabular}{cccc}
\hline Hipotesis & F $_{\text {hitung }}$ & $\mathbf{F}_{\text {tabel }}$ & Keterangan \\
\hline CSR terhadap ROA (5a) & 1,604 & 3,162 & Ditolak \\
CSR terhadap ROE (5b) & 3,863 & 3,162 & Diterima \\
CSR terhadap NIM (5c) & 0,082 & 3,162 & Ditolak \\
CSR terhadap CAR (5d) & 0,234 & 3,162 & Ditolak \\
\hline
\end{tabular}

Sumber : data diolah

\section{Pembahasan}

a. CSR terhadap ROA

Hasil menunjukkan CSR berpengaruh positif terhadap kinerja keuangan perbankan berstatus BUMN dan Swasta yang diproksikan dengan ROA. Hal ini menunjukkan bahwa semakin banyak pengungkapan aktivitas tanggung jawab sosial perusahaan dalam laporan tahunan perusahaan akan semakin meningkatkan kinerja keuangan perusahaan perbankan. Lingkungan sebagai faktor eksternal telah memiliki pengaruh nyata pada kinerja perusahaan. Keberhasilan perusahaan dalam menjalankan bisnisnya tidak terlepas dari kondisi lingkungan eksternal perusahaan. Lingkungan memiliki dampak nyata terhadap strategi operasional, perusahaan tidak dapat mengabaikan lingkungan bisnis sebagai faktor eksternal yang dapat mempengaruhi kinerja perusahaan. Kondisi ekonomi makro serta krisis ekonomi yang terjadi berimbas kepada kondisi keuangan perusahaan. Hal ini disebabkan perubahan yang terjadi di lingkungan usaha akan mempengaruhi perusahaan sehingga membutuhkan perubahan strategi yang akan dijalankan. Hasil penelitian ini sejalan dengan penelitian [10].

b. CSR terhadap ROE

Hasil tes menunjukkan bahwa CSR berpengaruh positif pada kinerja keuangan perusahaan perbankan berstatus BUMN dan Swasta yang diproksikan dengan ROE. Hasil tes hipotesis menunjukkan bahwa jika perusahaan meningkatkan pengungkapan CSR, maka kinerja ROE akan meningkat. Hal ini mengacu kepada kepedulian perusahaan kepada produk yang dapat didaur ulang, produk yang lebih tahan lama, produk dengan kualitas lebih baik, penggunaan sumber daya yang lebih bersih, serta penggunaan energi secara efisien. Sedangkan pada keterlibatan masyarakat mengacu kepada kepedulian perusahaan terhadap interaksi dengan masyarakat di sekitar perusahaan, antara lain dengan memberikan program beasiswa, sponsor dan pelatihan. Hasil penelitian ini sejalan dengan penelitian [10].

c. CSR terhadap NIM

Hasil menunjukkan CSR tidak berpengaruh terhadap kinerja keuangan perbankan berstatus BUMN dan Swasta yang diproksikan dengan NIM. Hal ini dapat diinterpretasikan bahwa semakin luas kepada program CSR belum tentu akan meningkatkan NIM. Hal itu dikarenakan ada pertimbangan lain bagi investor dalam menanamkan modalnya pada per perusahaan pertambangan. Meskipun melakukan pengungkapan informasi tetapi investor juga melihat pertimbangan lain dan mengutamakan kinerja lain misalnya kinerja keuangan, harga saham dan lain-lain sebagai pertimbangan untuk menanamkan modal pada sebuah perusahaan pertambangan. Hasil penelitian ini tidak sejalan dengan penelitian [4].

d. CSR terhadap CAR

Hasil menunjukkan CSR berpengaruh positif terhadap kinerja keuangan perbankan berstatus BUMN dan Swasta yang diproksikan dengan CAR. Hal ini menunjukkan bahwa semakin banyak 
pengungkapan aktivitas tanggung jawab sosial perusahaan dalam laporan tahunan perusahaan akan semakin meningkatkan kinerja keuangan perusahaan perbankan yang diproksikan dengan CAR. Pada dasarnya semakin tinggi nilai CAR maka akan semakin tinggi pula harga saham dikarenakan bank yang mempunyai CAR yang tinggi berarti bank tersebut memiliki permodalan yang cukup untuk melakukan kegiatan usahanya dan cukup pula untuk menanggung resiko apabila bank tersebut dilikuidasi. Semakin tinggi nilai CAR juga dapat menggambarkan bahwa bank tersebut semakin solvabel. Dengan kondisi seperti ini yaitu modal cukup maka bank akan dapat membiayai produk jasanya yang banyak, selain itu CAR yang besar sama dengan modal yang besar dan aktiva berisiko rendah. Hal yang pokok adalah dengan CAR yang tinggi, risiko dalam berinvestasi akan rendah. Hal seperti itulah yang akan mendorong para investor berbondong-bondong untuk membeli saham tersebut. Sesuai dengan hukum permintaan dan penawaran, maka kondisi tersebut akan meningkatkan harga saham. Rasio ini memiliki hubungan yang positif terhadap harga saham. Hasil penelitian ini tidak sejalan dengan penelitian [10].

\section{KESIMPULAN}

Kesimpulan yang diperoleh berdasarkan hasil analisis yaitu: CSR berpengaruh positif terhadap kinerja keuangan perusahaan perbankan berstatus BUMN dan Swasta Nasional yang diproksikan oleh ROA.CSR berpengaruh positif terhadap kinerja keuangan perusahaan perbankan berstatus BUMN dan Swasta Nasional yang diproksikan oleh ROE. CSR tidak berpengaruh terhadap kinerja keuangan perusahaan perbankan berstatus BUMN dan Swasta Nasional yang diproksikan oleh NIM. CSR berpengaruh positif terhadap kinerja keuangan perusahaan perbankan berstatus BUMN dan Swasta Nasional yang diproksikan oleh CAR.Terdapat perbedaan pen garuh pengungkapan CSR terhadap kinerja keuangan perusahaan perbankan berstatus BUMN dengan Swasta Nasional yang diproksikan oleh ROE.

Implikasi yang diperoleh pada penelitian ini yaitu dengan dilakukannya CSR diharapkan perusahaan terutama perbankan baik BUMN maupun Swasta dapat memberikan manfaat terhadap lingkungan dan masyarakat agar terbentuk keselarasan, keserasian dan keseimbangan antara perusahaan dan lingkungan serta masyarakat. Hal ini sesuai dengan teori kontrak sosial, di mana perusahaan memiliki kewajiban untuk memberi manfaat bagi masyarakat.

Saran untuk penelitian selanjutnya dapat dilakukan pada industri lain, misalnya perusahaan manufaktur atau pertambangan. Proksi rasio pada kinerja keuangan dapat diganti dengan rasio yang lainnya yakni BOPO, NOM, NPF, FDR, NPL, LDR dan lainnya.

\section{DAFTAR PUSTAKA}

[1] L. T. Panjaitan, "Bank Ramah Lingkungan," Penebar Plus: Jakarta, 2015

[2] Peraturan Bank Indonesia Nomor: 7/2/PBI/2005 Tentang Penilaian Kualitas Aktiva Bank Umum.

[3] M. Syahnaz, "Pengaruh Corporate Social Responsibility Terhadap Kinerja Keuangan Perusahaan Perbankan," Jurnal Ilmiah FEB Universitas Brawijaya, vol. 1, no 2, 2013.

[4] M. Hamdani, "Hubungan Pengungkapan Corporate Social Responsibility (CSR) Terhadap Kinerja Keuangan dan Harga Saham Pada Perusahaan LQ45," Jurnal Organisasi dan Manajemen, vol. 10, no. 1, pp 27-34, Maret 2014.

[5] Y. K. Susanto dan J. Tarigan, "Pengaruh Pengungkapan Sustainability Report terhadap Profitabilitas Perusahaan," Business Accounting Review, vol. 1, 2013.

[6] M. Yaparto, "Pengaruh Corporate Social Responsibility Terhadap Kinerja Keuangan Pada Sektor Manufaktur yang Terdaftar di Bursa Efek Indonesia Pada Periode 2010-2011," Jurnal Mahasiswa Universitas Surabaya, vol. 2, no. 1, 2013.

[7] Darmadji dan Fakhruddin, "Pasar Modal di Indonesia Edisi 3," Salemba Empat: Jakarta, 2012.

[8] Surat Edaran Bank Indonesia Nomor 3/30/DPNP tanggal 14 Desember 2001

[9] L. Dendawijaya, "Manajemen Perbankan," Ghalian Indonesia: Jakarta, 2005.

[10] Candrayanthi dan D. Saputra, "Pengaruh Pengungkapan Corporate Social Responsibility Terhadap Kinerja Perusahaan (Studi Empiris Pada Perusahaan Pertambangan di Bursa Efek Indonesia)," E-Jurnal Akuntansi Universitas Udayana, vol. 4, no. 1, pp. 141-158, 2013. 